\title{
A critical review of the literature on comfort of hearing protection devices: Analysis of the comfort measurement variability
}

Olivier Doutres, Franck Sgard, Jonathan Terroir, Nellie Perrin, Caroline Jolly, Chantal Gauvin \& Alessia Negrini

To cite this article: Olivier Doutres, Franck Sgard, Jonathan Terroir, Nellie Perrin, Caroline Jolly, Chantal Gauvin \& Alessia Negrini (2020): A critical review of the literature on comfort of hearing protection devices: Analysis of the comfort measurement variability, International Journal of Occupational Safety and Ergonomics, DOI: 10.1080/10803548.2020.1772546

To link to this article: https://doi.org/10.1080/10803548.2020.1772546

Accepted author version posted online: 21

May 2020.

Submit your article to this journal

山 Article views: 44

Q View related articles $\sqsubset$

View Crossmark data $₫$ 
Publisher: Taylor \& Francis \& Central Institute for Labour Protection - National Research Institute (CIOP-PIB)

Journal: International Journal of Occupational Safety and Ergonomics

DOI: $10.1080 / 10803548.2020 .1772546$

Check for updates

\section{A critical review of the literature on comfort of hearing protection devices: Analysis of the comfort measurement variability}

Olivier Doutres ${ }^{\mathrm{a} *}$ and Franck Sgard ${ }^{\mathrm{b}}$, Jonathan Terroirc, Nellie Perrin ${ }^{\mathrm{c}}$, Caroline Jolly ${ }^{\mathrm{b}}$, Chantal Gauvin ${ }^{\mathrm{b}}$, Alessia Negrini ${ }^{\mathrm{b}}$

${ }^{a}$ Department of Mechanical Engineering, École de Technologie Supérieure, ÉTS, 1100 rue Notre-Dame Ouest, Montréal, Québec, Canada, H3C IK3

${ }^{b}$ Institut de recherche Robert-Sauvé en santé et en sécurité du travail, IRSST, 505

Boulevard de Maisonneuve Ouest, Montréal, Québec, Canada, H3A 3C2

'Institut national de recherche et de Sécurité, INRS, 1 rue du MORVAN, 54500

Vandoeuvre-lès-Nancy, France

Corresponding author:

olivier.doutres@etsmtl.ca

Structured abstract:

Objective: This paper proposes a comprehensive literature review of past works addressing Hearing Protection Devices (HPDs) comfort with the aim of identifying the main sources of variability in comfort evaluation. Design: Literature review. Study samples: Documents were hand searched and Internet searched using 'PubMed', 'Web of Science', 'Google Scholar', 'ProQuest Dissertations and Theses Professional', 'Scopus' or 'Google' search engines. While comfort constructs and measurement methods are reviewed for both 
earplugs and earmuff HPD types, results and analyses are provided for earplugs only. Results: The literature shows that the multiple sources of the perceived comfort measurement variability are related to the complexity of the concept of comfort and to the various physical and psychosocial characteristics of the triad 'Environment/Person/Earplug' which differ from one study to the other. Conclusions: Considering the current state of knowledge and in order to decrease comfort measurements variability, it is advised to (i) use a multidimensional construct of comfort and derive a comfort index for each comfort dimensions, (ii) use exhaustive and valid questionnaires, (iii) quantify as much as triad characteristics as possible and use them as independent or control variables, and (iv) assess the quality of the earplug fitting and the attenuation efficiency.

Keywords: Earplug, hearing protection device, comfort, measurement variability, literature review.

Word count: 7155

\section{List of acronyms:}

CI: Comfort Index

FAES: Field Attenuation Estimation System

HPD: Hearing Protection Device

HLPP: Hearing Loss Prevention Program

NIOSH: National Institute for Occupational Safety and Health

NRR: Noise Reduction Rating 


\section{Introduction}

Hearing Protection Devices (HPDs) are commonly provided to workers to reduce their noise exposures and to protect them from Noise Induced Hearing Loss (NHIL). Their main function is characterized by the noise reduction they provide (quantified in north America by the Noise Reduction Rating NRR labeled on the HPD packaging) and whose minimum value should be targeted according to the surrounding noise level [1]. It is also well known that comfort aspects should not be overlooked since an HPD perceived as uncomfortable will not be used correctly or consistently and will rapidly become ineffective [2]. (Dis)comfort aspects should thus be understood and ideally related to the characteristics of the HPD, of the user and of his/her work environment. This would allow manufacturers to design more effective HPDs and safety professionals to propose workers with more adapted HPDs to them and their work environment. To this perspective, numerous field and laboratory studies investigated HPD comfort during the last 40 years as summarized in a recent literature review proposed by Doutres et al. [3]. The latter literature review shows that the numerous existing studies on HPD comfort differ on multiple factors: the construct of HPD comfort (see definition of 'construct' in [3]), the test methods and protocols, the type of HPDs and the test environments. Finally, a wide variability of HPD comfort measurements is pointed out which hampers (i) the comparisons of results across studies, (ii) the ranking of comfort attributes and (iii) the identification of HPD design improvements to target specifically the comfort aspects.

With the aim of proposing a comprehensive view of HPD comfort (and ultimately reducing the measurement variability induced by the various concepts and constructs of HPD comfort found in the literature), Doutres et al. [3] already proposed an holistic construct of 
comfort largely inspired by the one developed for clothes by Branson and Sweeney [4]. HPD comfort is a multidimensional construct composed of four dimensions: (1) the 'physical' dimension which is related to the user perception resulting from biomechanical and thermal interactions; (2) the 'acoustical' dimension which is related to the modification of the perception of both external and internal noises; (3) the 'functional' dimension which corresponds to the practical acceptability of HPDs and refers to the usability, efficiency and usefulness concepts; (4) the 'psychological' dimension, which refers to the well-being and the satisfaction of the user. In sum, HPD comfort is defined as a global perception characterising the balance between these four dimensions associated with the relationship between the user and his/her HPD in a given work environment. Branson and Sweeney [4] also further develop the concept of 'triad' (originally conceptualized by Fourt and Hollies [5]) constituted of the three 'environment/person/clothing' components having "physical and social-psychological dimensions that potentially influence physiological and/or perceptual responses and the subsequent comfort judgement for an individual in a given context" [4,p.100]. In the context of the present work, the triad comprises the work environment, the person (the HPD user) and the HPD. Physical and psychosocial dimensions of each triad component can be described by multiple intrinsic characteristics which can influence HPD comfort and thus help explaining the comfort measurement variability observed in the literature review of [3] (see Table 1).

This paper aims at summarising the possible sources of variability related (1) to the construct of comfort itself, (2) to its measurement methodology and (3) to the multiple triad characteristics which have been identified as potentially affecting comfort perception and thus evaluation. A better understanding of these characteristics will improve measurement 
methods and data analysis and, ultimately, enable to design more comfortable HPDs adapted to the user and his/her work environment.

\section{Effect of the construct on comfort evaluation}

The use of self-reported questionnaires to measure a subjective concept such as comfort implies several issues which can increase variability.

A first issue is related to the construct of comfort itself. Having different construct from one researcher to another inevitably leads to dispersions in the evaluation of comfort. For example, the Comfort Index (CI) indicator originally proposed by Epps and Casali [6] (which reached consensus), is usually calculated from the sum or from the average of all measured comfort attributes (referred to as Specific Comfort Level (SCL) in [3]), or of only the ones significantly associated to the main comfort construct. Consequently, the CI (as it is defined and generally calculated) depends on the construct itself and is specific to each study, which makes it difficult to compare results of different studies.

A second issue is related to the complexity of the comfort concept for which attributes may be probing more than one dimension. Participants' strategies can then be very variable and based on compromises. According to Brown-Rothwell [7], this elicits a selective response by the participants and enhance comfort measurement variability.

A third issue is related to the interpretation of the items. For instance, Casali et al. [8] mention the difficulty to know how the participant will interpret the antonyms used for their bipolar scales. This aspect is especially important for the 'comfortable /uncomfortable' scale used to assess the overall comfort in most studies [3]. BrownRothwell [7] explicitly incriminates the participant misinterpretation of questionnaire items 
(due to ambiguity in the wording) as a potential source of variability of comfort measurements. Furthermore, Park and Casali [9] developed a questionnaire by mixing two existing questionnaires specifically dedicated to earplugs or earmuffs. Some attributes (e.g., 'comfortable pressure/no comfortable pressure') initially proposed for earmuffs are then evaluated for earplugs, which can add confusion and blur in participants' responses. In order to avoid this kind of problems, a specific questionnaire can be dedicated to each type of protector (earmuff or earplug) $[6,8,10]$ or the distinction should be explicitly stated for problematic items [11]. This issue can also be related to the cognitive dissonance [12] that can be experienced by HPD users/participants in case of divergences between their feelings/thoughts/beliefs about the concept of comfort and the researchers' construct of comfort. For instance, a HPD user should experience negative emotions answering questions about 'maintaining in position', because for him/her, the comfort refers only to the notion of 'physical pain'. This can lead to misinterpretations for both (1) the overall dimension of comfort and (2) the attributes belonging to the various comfort dimensions (measured through questionnaire items). To limit participants' negative emotions and misinterpretations it is important to assess perceived comfort using validated questionnaires.

However, the development of a valid questionnaire which will enable to measure all attributes belonging to multiple dimensions requires rigorous procedures that takes into account the environmental, sociocultural and linguistic context of the research $[13,14]$. Furthermore, because of the cost associated to on site studies and the limited time available for the workers to participate in such research studies, HPD comfort questionnaires are often short and may be inadequate for assessing such a complex and multi-dimensional 
concept. Nevertheless, if one currently wants to progress in the understanding of the HPD comfort, this will require to include the greatest possible number of attributes belonging to the various comfort dimensions. As a concluding example of the importance of a global approach, one can cite the 'occlusion effect' [15]. Although this is deemed to be a significant discomfort attribute hampering communication for both listener and talker $[2,8,16]$, few studies incorporate dedicated items in their questionnaires. It is therefore very difficult to estimate its contribution to comfort in general.

\section{Effect of the 'Environment/Person/Earplug' triad characteristics on comfort} evaluation

This section presents the main intrinsic characteristics of the 'Environment/Person/Earplug' triad (see Table 1) expected to have a significant impact on earplug comfort for both field and laboratory studies, as well as to be important sources of comfort measurement variabilify. Some triad characteristics can be assessed through questionnaires (e.g. age, experience with HPD use). Other can be objectively measured with the help of specific sensors (e.g., air temperature, ambient noise characteristics). However, only few are usually considered as variables in subsequent statistical analyses. This finally hinders the identification of the triad characteristics affecting comfort despite the fact that this would make it possible to generalize the results and to help selecting/offering the most adapted HPD considering the user and his/her working environment. 


\subsection{Environment}

According to the dictionary definition of environment, the environment of participants involved in a HPD comfort study is all the circumstances, people, things, and events around them that influence their comfort perception. This triad component can then be described by multiple characteristics divided into physical or psychosocial dimensions and the following are discussed more in details since they emerged from the literature on earplug comfort: (1) the environmental conditions, (2) the acoustical environment, (3) the physical workload and (4) the implementation time of a hearing loss prevention program (HLPP). Prior to that, the two typical test environments (field or laboratory) used for comfort studies are briefly discussed.

\subsubsection{Field vs. laboratory test environments}

Field studies can be carried out in very different work environments. Comfort perception, and consequently its measurement, can then vary significantly [17]. Usually, field studies involving several participants do not specify the environment characteristics. This limitation can most probably be attributed to organisational difficulties (how to ensure that people are exposed to the same conditions) and to the important cost (time, money) of field studies. Thus, it is very difficult to have a sufficient number of participants per environment characteristics (e.g., same air temperature, acoustical environment, physical and mental workload). A sample big enough is however necessary to perform accurate statistical analyses. To the authors' knowledge, to date, only few field studies provide these analyses by including objective measurements of the environment as independent or control variables $[10,17,18]$. 
Laboratory studies are, a priori, more easily achievable, less expensive, more reproducible and thus more adapted to HPDs manufacturers during the design phase. Thus, comfort evaluations are often carried out in laboratory. However, conditions leading to realistic comfort measurements (as if they were carried out in the field) are not known yet (e.g. realism of the working environment, cognitive tasks to be performed, acoustical conditions, etc.). In an attempt to confront HPD comfort perceived in the laboratory and in the workplace, Park and Casali [9] make comfort laboratory measurements for naïve HPD users and for workers (daily HPD users) extracted from their workplace. Important differences (through the $\mathrm{CI}$ ) are found between the two groups and the authors mention that "it may be infeasible to devise a reliable short-term laboratory test which realistically estimates field HPD comfort" [9,p.151]. Possible sources explaining these discrepancies observed by Park and Casali [9] are presented and discussed in the present paper.

\subsubsection{Environmental conditions}

The workplace can be characterized by multiple environmental conditions such as air temperature, relative humidity, atmospheric pressure and air quality (dust). However, these properties are rarely measured and their effect on the assessment of HPD comfort has never been studied directly. Park and Casali [9] nevertheless suspect that the 'convenience' test results (questionnaire of the third group, see [3]) could be greatly modified if environmental conditions were studied as independent or control variables. They then specify that the effect of environmental factors deserves to be investigated in future studies on HPDs comfort. Indeed, as mentioned by many authors $[2,11,19,20]$, environmental conditions are known to influence HPD comfort (e.g. earplug are preferred in hot environment and 
earmuff in cold environment). Arezes et al. [11] observe that, for HPD users working in a hot environment, the 'ability to dissipate heat' and 'ability to absorb perspiration' are important attributes of comfort perception (ranked 3rd and 5th out of 9, respectively). They also precise that "this priority order would, certainly, be different" [11,p.7] if their study was carried out in a cold environment.

\subsubsection{Acoustical environment}

The workplace acoustical environment is usually composed of ambient noise associated with useful sounds such as warning or broadcasting signals, machinery sounds (providing information about the quality of the manufacturing process or the machine health) and coworkers' speech. All differ in their intensity, frequency and temporal characteristics. Moreover, acoustical environments obviously differ significantly from one field study to another. This may partly explain why acoustical comfort attributes are either considered as important $[10,18,19,21]$ or non-important $[11,22,23]$ contributors to the perceived overall comfort. However, the relationship between the acoustical environment characteristics and the overall comfort has rarely been studied directly. A few field studies mention the global equivalent sound pressure level $L_{e q}$ of the ambient noise for each participant or group of participants and include this characteristic as an independent variable [10,18]. As a first example, Sweetland [10] selects workers from a single company exposed to 15 different acoustical environments. Next, he divides them into two categories: those operating in a ‘quiet' (for $L_{e q}<90 \mathrm{~dB}(A)$ ) or 'noisy' (for $L_{e q}>90 \mathrm{~dB}(A)$ ) environment. He then analyzes the effect of these two modalities on a 'total interference' comfort score computed from the scores of four attributes related to the acoustical dimension of comfort (i.e., 'difficulty 
in hearing the warning signals', 'difficulty in hearing the messages broadcasted by the company', 'difficulty in man-man communication' and 'difficulty in analyzing the performance of the machine via the noise it emits'). For the two studied earplugs, Sweetland shows that the 'total interference' score depends on the acoustical environment, the quiet one implying more acoustical discomfort. As a second example, Gonçalves et al. [18] measure the HPD comfort in three units from a lumbering company having different acoustical properties (each unit is characterized by its minimum and maximum measured noise level). For the tested premolded earplug, the mean overall comfort was better in the highest noise level unit and authors presume a cause and effect relationship. As a confirmation of the potential impact of the acoustical environment on the perceived comfort, the National Institute for Occupational Safety and Health (NIOSH) team mentions that their field study should have dissociated workstations subjected to continuous or impulse noise [24]. Indeed, they suspect a greater acoustic discomfort (related to the feeling of under-protection) for workers exposed to an impulsive sound environment and wearing custom earplugs which have, in this study, a lower acoustic attenuation level than the usual earplugs worn by these workers (see also section 3.2.3).

One can note that most of laboratory studies employ the term 'comfort' for designating subjective perceptions related to the mechanical contact between the HPD and the body [3]. Thus, the associated tests are mostly carried out in quiet environments (i.e., the participant are not exposed to an artificial occupational noise), which then artificially distinguish between the physical and acoustic dimensions of comfort. To the authors' knowledge, only two laboratory studies on HPD comfort are carried out in a noisy 
environment [7,25] but its effect is not investigated: only one noise is used and its characteristics remain the same during the entire experiment.

In fact, laboratory studies, which analyze rigorously the interactions between the acoustical environment, the wearer hearing condition and the HPD, focus on the awareness of sounds in the surrounding environment (e.g., speech intelligibility, sound localization, warning signals perception) [26-33] but do not approach the acoustical or the global comforts associated to the HPD use. The latter studies investigate the effect of the HPD by scoring speech recognition, noise source localization or warning signals detection in masking noise. Early intelligibility experiments on normal-hearing individuals [26,30,31] partly confirm the findings of Sweetland (1983) regarding acoustical comfort: HPDs hamper speech intelligibility for background noise below a certain level (around $80 \mathrm{~dB}$ in [30] and $88 \mathrm{~dB}$ in [26]) and enhance it above this level. Intelligibility improvement in high noise level is attributed to a release from cochlear overload [2] whereas the degradation in low noise levels is due to the fact that the noise level under the HPD is sufficiently low so that a greater amount of speech cues are attenuated below audibility. Using the speech recognition model developed by Giguère et al.[29], Giguère and Berger [34] show that the recognition of a shouted speech by a normal-hearing individual immerged in a loud noise environment (of 95-96 $\mathrm{dB}(A)$ ) is always improved by the HPD. This positive effect is independent of the surrounding noise spectrum or of the HPD attenuation function. Likewise, Giguère and Berger [35] show that the sound detection thresholds in noise for normal-hearing individuals is hardly affected by use of HPDs, even for a low-frequency ambient noise. These conclusions differ in the case of an individual with hearing loss (as discussed in section 3.2.4). Regarding other characteristics of both the ambient noise and 
the useful sounds, laboratory studies on situational awareness drawn other interesting conclusions that should be kept in mind during comfort field studies since they can also participate to measurement variability: (1) the (useful) signal to (ambient) noise ratio should be quantified since it enhances useful sounds awareness when is it increased, (2) the temporal characteristics of the noise should be quantified since modulated background noise can increase intelligibility for normal-hearing individuals [27,36]. Finally, it is worth noting that the positive effect of HPD on speech intelligibility (observed in laboratory studies) is not reflected in field comfort studies. This could be linked to the fact that researchers are more regularly asking about the absence of discomfort than about the presence of comfort.

\subsubsection{Physical workload}

Work activities can also affect the perceived comfort. It can be characterized by many factors (e.g., type of work, work duration, physical load, mental load, necessity to wear other personal protective equipment) but only the effect of the physical workload on HPD comfort has been investigated so far. To the authors' knowledge, the only study investigating this effect is performed in laboratory environment by Park and Casali [9]. In their study, the effect of the physical workload on HPD comfort is evaluated with the help of naive HPD users before and after two movement modalities: jaw movement (participants read at loud, chew gum and eat snacks during 30 minutes) and activity movement (participants use a work simulator and perform highly kinematic movements during another 30 minutes). It is worth mentioning that, in their study, the CI is built from 4 attributes of the physical and functional dimensions of comfort and thus more likely 
characterizes a physical-functional comfort. For the two tested earplugs (one premolded and one roll-down foam), they show that the physical-functional comfort and the overall perception were not noticeably affected by jaw or activity movements. They also precise that this conclusion may have been different if environmental stressors had been added (e.g., increased heat). In other studies, Casali and Park $[37,38]$ show that, depending on the earplug type, highly dynamic, kinematic workloads may decrease the quality of the fit and generate attenuation loss. The workload (and most probably other characteristics of the work environment) could thus affect attributes of the acoustical dimension of comfort as well as other dimensions (see section 4Effect of earplug fitting and attenuation).

\subsubsection{Hearing loss prevention program}

It is known that HLPP should include proper training to HPD use/fit since it is associated to a considerable improvement of earplug attenuation efficiency $[39,40]$ (see section 4). Gonçalves et al. [18] investigates HPD comfort in three units from a lumbering company which differ in their HLPP implementation time (from 1 year to 6 years). The unit with the longer HLPP implementation time is found to be the one for which the workers (i) give the most importance to the aspects of the HPDs (e.g., attenuation, pressure texture) and (ii) better evaluate the overall comfort provided by earplugs.

\subsection{Person}

The following characteristics can be found in the literature to differentiate HPD users on their perception of comfort: (1) outer ear morphology, (2) gender and age, (3) experience with HPD use and (4) hearing condition. 


\subsubsection{Outer ear morphology}

The morphology of outer ear is so unique that personal identification could be assessed from the various curves and dimensions of the pinna $[41,42]$. An important inter-individual variation in earcanal size and shape is also reported in multiple studies [43-45]. Wheeler and Glorig [45] mention that the mean diameter of the earcanal ranges between 8 and 12 $\mathrm{mm}$ (they detail this dimension variability citing the work of Cunningham and Robinson [46]). They also bring up the important variability observed on the position of the tragus relatively to the earcanal entrance and the possible negative impact on both earplug insertion and mechanical pressure exerted by the earplug if the tragus extends too far backwards over the canal opening.

The large inter-individual variations in earcanal size and shape may logically lead to a large variability in the earcanal/earplug interactions (e.g., normal and shear stress, skin deformation). Thus, while the difference in earcanal morphology can be considered as a possible source of (dis)comfort measurement variability, it has never been investigated directly. Indeed, measuring such anatomic properties is not straightforward and can increase significantly the complexity and cost of comfort studies. To our knowledge, only one comfort study [47] assesses some earcanal properties: the equivalent diameter of the earcanal entrance using the Eargage ${ }^{\mathrm{TM}}$ tool [48] and the equivalent earcanal volume using a tympanometer. They found no relations between the two properties and thus advise to use the Eargage $\mathrm{T}^{\mathrm{TM}}$ tool only as a complementary tool for selecting the correct earplug. Furthermore, these earcanal properties are not used to analyze comfort and attenuation results. In future comfort studies, other characterization methods such as scans of 
participants' physical earmold impressions or digital ear scanning $[49,50]$ could be used to have a more precise description of participants' earcanal morphology and relate it to comfort.

\subsubsection{Gender and age}

Multiple studies about outer ear morphology report that male and female are not equal regarding the earcanal properties [51-53]. Yu et al. show that "the average height and width of earcanal openings, and the average depth of the first bend for men are generally longer, wider and deeper than those for women" [52,p.50]. Darkner et al. also state that "males in general are more prone to deformation of the ear and canal" [53,p.807].

The gender of participants is in fact usually reported in comfort studies but rarely used as an independent variable. Most of the participants of the studies included in this review were men, which made the comparison more difficult or rare. Nevertheless, Bockstael et al. notice that male evaluate the fit to be better than female participants do [54] but find no significant differences in speech recognition [27]. Bjorn et al. [55] do not observe any gender effect in earplug use habits among U.S. navy flight deck crews. The relationship between gender and perceived comfort therefore remains unknown at this stage of knowledge. Further studies should take into account the gender variability to assess if differences exist between men and women.

Based on the information available in the studies considered in this review, participants were aged between 18 and 72, and the mean age was 31. As mentioned by Spomer et al., "age may influence HPD preferences and hearing sensitivity, but this was not assessed" [56,p.368]. Future studies should include the age-groups variability (e.g., young vs senior 
participants) in order to describe the relationship between age and the experience with HPD use, taking into account the outer ear morphology and the hearing condition. For instance, differences could help to define specific HLPP targeting workers exposed to noise following their age and career stages.

\subsubsection{Experience with HPD use}

The experience with HPD use is usually investigated from the two following modalities: (1) naïve participants who do not work in a noisy environment and do not use HPD in their work or leisure, and (2) non-naïve participants who work in a noisy environment, do usually use HPD and who have to wear their usual or different HPDs during the experiment.

For long-term non-naïve users, a bias can be introduced in favor of (or against) a specific HPD [8]. This bias can be significant [57] but can hardly be avoided in field studies. In order to eliminate this bias, most laboratory studies involve only naïve participants [6$8,25,47,58]$. While reducing the complexity and costs of the experimental procedure, this also may introduce a bias related to the lack of familiarity with HPDs. A few studies involve naïve and non-naïve participants $[7,9,10,23,25]$ and all show significant differences. In general, non-naive users are "more discerning and tend to produce more extreme ratings, in both the most favourable and most unfavourable directions"[7,p.66][18,23]. Non-naïve users are also reported to give more importance to HPD characteristics, to have a better knowledge of the HPDs and thus to provide more detailed and technical opinion on HPD characteristics $[18,23]$. Regarding the functional dimension of comfort, the laboratory study of Park and Casali [9] shows that naïve participants tend to find protectors more comfortable than non-naïve participants do. Regarding the acoustical dimension, 
Sweetland [10] observes that the participant's experience with HPDs use can influence the 'total interference' score (see section 3.1.3): the greater the experience, the lower the associated discomfort. He thus notes greater discomfort for naïve participants, particularly when exposed to low noise levels. Davis et al. [57] observe that some workers who tested custom moulded earplugs complained about an insufficient attenuation (despite fit-test evidence of the contrary). Authors assume that it could be due to the fact that these workers "have become habituated to being overprotected" [57,p.D128]. Comparing speech intelligibility score between a group of non-naïve participants (workers used to HPDs and noisy environments and with a moderate noise-induced hearing-loss) and a control group of naïve participants (university staff familiar with listening to speech audiometric material and having normal audiograms), Acton [59] points out that, despite their moderate hearing loss, the non-naïve group outperforms the naive one for a speech to noise ratio of $-5 \mathrm{~dB}$. He attributes this to a conditioning process on initial noise exposure and mention that "'getting used to the noise', is, in fact, a significant factor in speech intelligibility against a background noise" [59,p.5531. These participants were then doubly accustomed: accustomed to wearing HPD and accustomed to operating in a noisy acoustic environment.

Both naïve and non-naïve participants involved in comfort studies are usually asked to wear new earplugs (i.e., unknown to them). All field and laboratory studies are thus confronted to two important points conceptually divided here into two chronological periods: (i) a short-term period (beginning just after the earplug insertion) where the participant begin to feel discomfort and (ii) a mid-term period where habituation may occur (if the test protocol is sufficiently long for this to happen, see below). These two periods are part of the process of gaining experience in a given earplug and the comfort perceived 
during these periods is also affected by the general experience with HPD use (naïve vs. non-naïve users).

As mentioned above, the short-term period corresponds to the period where the participant is just given a new HPD and start feeling discomforts. Park and Casali [9] show that for naïve participants, the perceived (physical-functional) comfort is stable during the 2 hours of use in the laboratory (which is not the case for earmuffs). In their field study, Hsu et al. [21] ask the participants to assess the moment from which they begin to feel discomfort. The survey shows that $48.4 \%$ of respondents feel discomfort after 1 hour; and only $25.0 \%$ did not feel discomfort after more than 2 hours. Bockstael et al. [19] also report that most of the participants of their field study quickly perceived discomforts. This short-term period is thus suspected to be a source of inter-individual variability which reduces the ability to compare results across studies and especially for 1 or 2 hours short-term comfort laboratory protocols. It is thus recommended that the minimum wear time in laboratory studies exceeds this short-term period, Furthermore, according to the proposed multidimensional construct of HPD comfort [3], there could be different short-term period for physical, acoustical, functional and psychological dimensions.

A mid-term habituation, also referred to as acclimatization, is also pointed out in the literature and particularly for attributes of the acoustical dimension of comfort. While investigating the evolution of the 'total interference' score (see section 3.1.3) as a function of time for naïve and non-naïve participants involved in an 8 weeks test campaign, Sweetland [10] notices that the acoustic discomfort decreases with time for both types of participant but in a much more important way for the naïve ones. Both then end up feeling 
similar acoustical discomfort. Brown-Rothwell [7] investigates HPD comfort in the laboratory with naïve participants involved in five experimental sessions. Like Sweetland, he observes an improvement in the perceived 'ease of communication' as the experiment progresses, thus suggesting a significant learning effect. In the case of trumpet players, Killion [60] also mentions a certain acclimatization time (only a few weeks) necessary to adapt themselves to loudness and timbre changes due to earplug wearing. A duration of several months are also reported for musicians or hearing aid users to be able to get accustomed to their in-ear device $[61,62]$. In the same vein, an acclimatization time to adapt to physical discomforts is largely accepted in the literature but not very documented. Behar, Segu and Russo [63] mention that some earplugs may appear uncomfortable when just inserted, then become forgotten by users. Stork and Gateway [64] (citing [65]) state that an earplug worn for the first time is perceived as uncomfortable (even if well inserted) and becomes comfortable when worn routinely (see also sec. 11.2.4 in the standard CSA Z94.214 [1]). Contrarily, while measuring a compound of the physical and functional comfort dimensions (with their CI) for non-naïve participants involved in a 6 weeks test campaign and wearing one-size-fits-most earplugs (roll-down foam or premolded earplugs), Park and Casali [9] do not observe any influence of the duration of use. Although it is known from field observations that a certain period is necessary to accommodate to custom earplugs $[57,66,67]$, it has not been investigated in comfort studies so far. In the literature, this period is mostly related to functional and physical attributes of comfort (e.g., insertion, mechanical pressure) and can take "an average of 6 days with a maximum of 60 days" for deepmoulded earplugs [67,p.11]. The literature thus indicates that comfort studies on earplugs should be performed over extended period of time. 


\subsubsection{Hearing condition}

As for the acoustical environment, the hearing condition is expected to mainly affect the attributes of the acoustical dimension of comfort. But in fact, very few comfort studies carried out in the field mention it for each participant or group of participants and analyze its characteristics as independent variables. Gonçalves et al. [18] observe that workers with altered audiograms are more likely to negatively evaluate the use of HPD with regard to 'aural communication easiness'. Svensson et al. [68] note that the difficulty in hearing useful noise' is more common for normal hearing workers and workers with highfrequency hearing loss than those with other types of hearing loss (citing the work of [69] on chemically induced hearing loss).

Studies rigorously analyzing the interactions between the hearing acuity of the user, the HPD properties and the acoustical environment are mainly interested in the awareness of sounds in a surrounding environment (e.g., speech intelligibility, sound localization, warning signals perception) $[28,29,32,33]$. Contrary to normal-hearing individual (already covered in the section 3.1.3), Giguère and Berger [34] confirm that HPD use decreases the speech recognition for hearing impaired individuals since audible speech cues fall below the hearing threshold. They show that this decrement is worsen for (1) ambient noises having important low frequency content and (2) HPDs providing important attenuation or high attenuation slope. For hearing-impaired individuals, important and useful sounds from the acoustical environment can be inaudible or masked due to the combination of (1) the severity of hearing loss, (2) the attenuation properties of the HPD and (3) the spectral content of the ambient noise. 
The hearing acuity of workers is mostly quantified through an audiogram which (i) measures the minimal sound pressure required for pure-tone detection and (ii) partly quantifies hair cell damage. Recent studies on the animal auditory system demonstrate that noise can also damage the synaptic connections between hair cells and cochlear neurons without affecting threshold detection [70-72]. This cochlear synaptopathy-driven functional deficit, also known as 'hidden hearing loss', is suspected to impair speech understanding in noisy environments. Speech-in-noise testing could thus be recommended in future comfort studies in addition to audiograms to have a more complete objective measurement of participants' hearing acuity [34,71].

\subsection{Earplug}

A large variety of earplugs can be found on the market. They essentially differ from their shape, material, texture and color. Most earplugs tested in comfort studies are from the three following families: "Roll-down foam" earplugs (made of compressible foam), "Premolded" earplugs (made of a semi-rigid rod covered with one or several flexible flanges) and "Custom moulded" earplugs (usually made from earcanal molds) [2,3]. The following general characteristics are associated to more (physically) comfortable earplugs in [8]: softer, more rounded, smoother, slightly looser, slightly shallower and less painful. The various comfort/discomfort attributes commonly attributed to the three aforementioned earplug families are now presented.

Roll-down foam earplugs are commonly found difficult to insert $[7-9,11,47,56]$ and to provide too much attenuation $[11,56]$. They are also found to have a good maintaining in position [7,9] and able to disseminate heat in [11]. Comfort provided by this type of earplug 
is notably sensitive to the fitting procedure [9] (see section 4). From a psychosocial perspective, roll-down foam earplugs are found 'attractive' and 'acceptable' by users in [9].

Premolded earplugs with silicone flanges provide important physical discomforts [18] (more than other types of earplugs in [6,8]). However, they are found easy to insert [18] (easier to be inserted than other types of earplugs in $[8,9,47,56])$.

Custom moulded earplugs are preferred to one-size-fits-most earplugs in $[67,73]$. They are also preferred by workers wearing earplugs over a long period in $[19,67]$. This type of earplugs (when equipped with acoustic filters) is also preferred by some musicians "because of their frequency independent attenuation, better fit, and better protection" [74,p.163]. However, other musicians in the same study "found the fitting of the custom moulded earplugs more time consuming" (p.163) (compared to disposable earplugs) and "reported that the custom moulded earplugs changed the perceived sound quality, were warm and sweaty" (p.163) and attenuate more than the disposable earplugs. Custom moulded earplugs are also found physically uncomfortable in [7]. This discomfort is attributed to the used silicone which "was not adequately flexible to cope with the displacement of the ear canal and tragus produced by jaw movements" [7,p.83].

\section{Effect of earplug fitting and attenuation on comfort evaluation}

The two characteristics discussed here (i.e. the earplug fitting and its attenuation) result from the complex combination of the 'Environment/Person/Earplug' triad components and thus can be affected by characteristics belonging to all of them. 
The earplug fit is here conceptually divided into two chronological phases which can be affected by different triad characteristics. The first phase occurs prior to any interaction between the earplug and the earcanal, and may affect the fit quality because of various triad characteristics such as (1) the application of a HLPP (including or not a training for proper HPD use) or the necessity to insert/remove regularly the HPD during work, (2) the person's previous experience with HPDs or his/her hand dexterity and (3) the earplug material and design (e.g., difficulty in rolling or improper expansion time for roll-down foam earplugs, the presence or the absence of stem, corded or uncorded earplug) or the quality of the instructions provided by the manufacturer. The second phase occurs once the earplug is positioned inside the earcanal (the interaction is effective). The quality of the fit and its stability with time are then affected by multiple triad characteristics such as (1) the work activities, the physical load (involving body, head or jaw movements), the ambient temperature or the necessity to wear other personal protective equipment which may interact with the earplug, (2) the size, shape, hairiness or flexibility of the earcanal or the propensity to generate ear wax or sweating and (3) the earplug material and design (e.g., softness, weight, texture).

The quality of the fit is rarely reported from comfort studies most probably because of the complex evaluation of the earplug/earcanal interaction properties. Nevertheless, at first sight, the fitting procedure is associated to the training provided (or not) to the user. Two types of fitting procedure are usually investigated: (1) fit by the participant himself "using only the manufacturer's package instructions without any experimenter intervention or guidance" $[9, p .156]$ (usually referred to as "subject-fit" condition) and/or (2) fit by the participant himself with prior training provided by the experimenter (usually referred to as 
"trained-fit" condition). The subject-fit procedure is preferred to simulate common practice $[9,11,58]$. Park and Casali [9] show that the fitting procedure mostly impacts the comfort rating of a roll-down foam earplug (which is not the case for the tested premolded earplug). For this earplug, the subject-fit procedure is associated with a greater physical comfort most probably because "the earplugs were inserted more deeply in the trained-fit condition and elicited more (physical) discomfort as a result" [9,p.161]. On the contrary, this earplug is found to be more difficult to insert, to present a propensity to loosen (functional dimension) and to become less attractive (psychological dimension) to experienced users when asked to follow the trained-fit procedure. While measuring comfort (through the CI based on the questionnaire of [8]) and attenuation for normal-hearing naïve participants wearing roll-down foam or formable earplugs and using the subject-fit condition, Byrne et al. find that "the subject's ability to correctly seat the earplug was the source of much of the variability" [58,p.91].

As mentioned previously, the quality of the fit is usually assessed indirectly from the fitting procedure (subject fit versus trained fit) but more direct method could also be considered. The most practical one (in terms of time and cost) is based on a simple visual inspection that can be made by another person $[2,75]$. However, this technique is not accurate and could only be applied to roll-down foam earplugs for which the insertion depth strongly influences the resulting attenuation [2,76]. Visual cues are much more difficult for other families such as premolded or push-to-fit foams earplugs for which the coupling between the earplug and the earcanal is internal. Visible part of the earplug (e.g., the stem) may then not provide sufficient information about the fitting quality. For the later earplug families, Berger and Voix [2] provide fitting tips to be performed by the wearer (e.g., 'the pump 
test'). A more robust technique, recently standardized in the [77], is based on fit-testing systems technically referred to as Field Attenuation Estimation Systems (FAES). These systems assess the achieved attenuation and thus indirectly estimate the quality of the acoustic seal or 'acoustical fit'. FAES systems are promising tools to train workers for proper earplug insertion or to check the quality of the acoustical fit during the work shift $[75,78,79]$. However, it is worth noting that a 'good' fit may not be similar for every comfort dimensions. According to the multidimensional construet of HPD comfort proposed by Doutres et al. [3], there could be different optimum fits for acoustical, physical, functional and psychological dimensions. As evidence of these competing behaviors, Byrne et al. observe that (physical) "comfort and attenuation are inversely related for the naïve subjects (and the two types of [tested] earplugs) evaluated in [their] study” [58,p.91]. This observation confirms results from previous comfort studies for which the comfort was evaluated as a function of the type of fit (subject-fit versus trained fit) $[9,80]$ : comfort was found to be greater in the case of the subject-fit condition although it was also associated to a poorer earplug attenuation efficiency.

Due to the high variability of the human earcanal morphology (see section 3.2.1) and of earplug fitting, the attenuation provided by a given earplug is subjected to an important measurement dispersion as commented in the extensive literature on this topic [76,81-83]. This inter-individual variability, inherent to the calculation of the attenuation efficiency, is even reported by [1] as a limit to a reliable prediction of the level of exposure under the HPD. This could then influence the inter-individual variability in perceived (dis)comfort of attributes belonging to the acoustical dimension of comfort. Viallet et al. [84] show, via numerical finite element analysis, that this variability could be attributed to acoustic 
leakage around the earplug for low frequencies $(f<1 \mathrm{kHz})$ and by the inter-individual variability of the earcanal geometry for medium and high frequencies $(1 \mathrm{kHz}<f<5 \mathrm{kHz})$. According to the section 3.2.4, the effect of this variability could impact the evaluation of the acoustical comfort attributes, mostly for hearing-impaired individuals for which the situational awareness is more impacted by the HPD attenuation characteristics (global attenuation and attenuation slope) [34,35]. HPD attenuation should thus ideally be quantified in comfort studies, e.g. using FAES systems according to [77].

\section{Conclusion}

In light of this literature review dedicated to earplug comfort, multiple sources of measurement variability have been presented. Some are related to the diversity of researchers' construct of comfort and to the possible divergence between these constructs and participants' own concepts of comfort. Other sources of variability can be attributed to the multiple characteristics of the 'Environment/Person/Earplug' triad which differ from one study to the other. In order to improve our understanding of perceived HPD comfort and to reduce comfort measurement variability, it is thus advised (i) to use the multidimensional construct of comfort proposed by Doutres et al. [3] and derive a comfort index for each dimensions (i.e., physical, acoustical, functional, and psychological) as well as an overall comfort index, (ii) to use exhaustive and valid questionnaires in order to grasp the complexity of this multidimensional construct, (iii) to quantify as much triad characteristics as possible and to use them as independent or control variables to identify the most significant ones, (iv) to assess the quality of the earplug fitting and the attenuation efficiency, even for field studies. 


\section{Acknowledgements}

The authors acknowledge IRSST (Montréal, Québec, Canada) and INRS (Vandoeuvre-lèsNancy, France) for funding this research. The authors would also like to thank Marie Stewart from ÉTS library (Montréal, Québec, Canada) for finding/digging old and “hard to find" references. 


\section{Tables}

Table 1: Characteristics of the triad 'Environment/Person/Earplug' expected to have a significant impact on HPD comfort by field and laboratory studies. Characteristics are divided into physical or psychosocial dimensions.

\begin{tabular}{|l|l|l|}
\hline $\begin{array}{l}\text { Component } \\
\text { of the triad }\end{array}$ & Dimension & Characteristics \\
\hline Environment & Physical & $\begin{array}{l}\text { Environmental conditions: air temperature, relative humidity, } \\
\text { atmospheric pressure, air quality (dust). } \\
\text { Acoustical environment: global level, spectral and temporal } \\
\text { characteristics of the workplace noise and of the useful sounds } \\
\text { (speech, warning signals, machinery sounds), talker-listener } \\
\text { distance, alarm-listener distance. }\end{array}$ \\
\cline { 2 - 4 } & Psychosocial & $\begin{array}{l}\text { Physical workload. } \\
\text { Implementation time of HLPPs. }\end{array}$ \\
\hline Person & Physical & $\begin{array}{l}\text { Outer ear morphology: size and shape of the earcanal, position of } \\
\text { the tragus. } \\
\text { Hearing condition: audiogram, speech-in-noise testing. }\end{array}$ \\
\cline { 2 - 4 } & Psychosocial & $\begin{array}{l}\text { Biological: gender and age. } \\
\text { Experience with HPD use: naïve or non-naïve HPD users. }\end{array}$ \\
\hline Earplug & Physical & $\begin{array}{l}\text { Shape, softness, weight, texture, embedded technology (presence of } \\
\text { acoustic filters, active Vs passive) }\end{array}$ \\
\cline { 2 - 3 } & Psychosocial & $\begin{array}{l}\text { Attractiveness of the product (ex, custom molded, active products), } \\
\text { quality of the instructions for proper fit. }\end{array}$ \\
\hline
\end{tabular}




\section{References}

[1] Canadian Standards Association. Hearing protection devices - Performance, selection, care, and use. 2014. Standard No.: CSA Z94.2-14.

[2] Berger EH, Voix J. Hearing protection devices. In : The Noise Manual, 6th edition (in press). American Industrial Hygiene Association. Falls Church (VA): AIHA Press; Forthcoming.

[3] Doutres O, Sgard F, Terroir J, et al. A critical review of the literature on comfort of hearing protection devices: definition of comfort and identification of its main attributes for earplug types. Int J Audiol. 2019;58:824-833.

[4] Branson DH, Sweeney MM. Conceptualization and Measurement of Clothing Comfort: Toward a Metatheory. Crit Link Text Cloth Theory Method Pract. International Textiles and Apparel Association ITAA Special Publication. Monument (CO): S. Kaiser and M.L. Damhorst; 1991.p. 94-105.

[5] Fourt L, Hollies NRS. Clothing comfort and function. Marcel Dekker Inc. New York (NY); 1970.

[6] Epps BW, Casali JG. Hearing Protection Device Comfort and User Preference: An Investigation and Evaluation Methodology. Proc Hum Factors Soc - 29th Annu Meet. Santa Monica (CA); 1985. p. 814-818.

[7] Brown-Rothwell DJ. The comfort of earplugs-basis for a descriptive model [Master's thesis (unpublished)]. [England]: University of Southampton; 1986.

[8] Casali JG, Lam ST, Epps BW. Rating and Ranking Methods for Hearing Protector Wearability. Sound Vib. 1987;21:10-18.

[9] Park M-Y, Casali JG. An empirical study of comfort afforded by various hearing protection devices. Laboratory versus field results. Appl Acoust. 1991;34:151-179.

[10] Sweetland KF. Physical predictors for earmuff comfort. [Master's thesis]. [England]: Loughborough University of Technology; 1983.

[11] Arezes PM, Abelenda C, Braga AC. An evaluation of comfort afforded by hearing protection devices. Proc AHFE 2008. 2008. p. 1-8.

[12] Festinger L. A Theory of Cognitive Dissonance. California: Stanford University Press; 1962.

[13] Clark LA, Watson D. Constructing Validity: Basic Issues in Objective Scale Development. Psychol Assess. 1995;7:309-319. 
[14] Corbière M, Fraccaroli F. La conception, la validation, la traduction et l'adaptation transculturelle d'outils de mesure : des exemples en santé mentale. Méthode Qual Quant Mixte Dans Rech En Sci Hum Soc Santé. Québec, (QC), Canada: Presses de l’Université du Québec; 2014. p. 577-620.

[15] Carillo K, Doutres O, Sgard F. Theoretical investigation of the low frequency fundamental mechanism of the objective occlusion effect induced by boneconducted stimulation. J Acoust Soc Am. 2020;147:3476-3489.

[16] Tufts JB, Frank T. Speech production in noise with and without hearing protection. J Acoust Soc Am. 2003;114:1069-1080.

[17] Arezes PM, Miguel AS. Hearing Protectors Acceptability in Noisy Environments. Ann Occup Hyg. 2002;46:531-536.

[18] Gonçalves CGO, Lüders D, Guirado DS, et al. Perception of hearing protectors by workers that participate in hearing preservation programs: a preliminary study. CoDAS. 2015;27:309-318.

[19] Bockstael A, Botteldooren D, De Bruyne L, et al. Personal hearing protection and comfort: indispensable but not a matter of course. Proc 9th Eur Congr Expo Noise Control Eng. Prague, Czech Republic: EAA; 2012. p. 335-339.

[20] Cooper S, Morrill M. Comfort is the Secret to Success. Occup Health Saf. 2014;83:16-18.

[21] Hsu Y-L, Huang C-C, Y॰ C-Y, et al. Comfort evaluation of hearing protection. Int J Ind Ergon. 2004;33:543-551,

[22] Ivarsson A, Toremalm NG, Brühl P. Eczema, itching, heat and humidity problemsImpediments to the effective use of hearing protectors. Proc Internoise 1990. Göteborg, Sweden: Institute of Noise Control Engineering; 1990. p. 1093-1096.

[23] Schulz G, Rublack K, Meister A, et al. Vergleichende untersuchungen der dâmmwirkung und der trageeigenschaften von gerhörschutzmitteln am arbeitsplatz [Comparative investigations of the insulating effect and the wearing properties of hearing protector means at the place of employment]. Z Gesamte Hyg Ihre Grenzgeb. 1983;29:93-98.

[24] Murphy WJ, Davis RR, Byrne DC, et al. Advanced Hearing Protector Study Conducted at: General Motors Metal Fabricating Division Flint Metal Center - Flint, MI January 2004-February 2005. Washington (DC): NIOSH; 2007. Report No.: 312-11a. .

[25] Bhattacharya SK, Tripathi SR, Kashyap SK. Assessment of comfort of various hearing protection devices (HPD). J Hum Ergol (Tokyo). 1993;22:163-172. 
[26] Acton WI. Effects of Ear Protection on Communication. Ann Occup Hyg. 1967;10:423-429.

[27] Bockstael A, De Coensel B, Botteldooren D, et al. Speech recognition in noise with active and passive hearing protectors: A comparative study. J Acoust Soc Am. 2011;129:3702-3715.

[28] Brown AD, Beemer BT, Greene NT, et al. Effects of Active and Passive Hearing Protection Devices on Sound Source Localization, Speech Recognition, and Tone Detection. Snyder J, editor. PLoS ONE. 2015;10:e0136568.

[29] Giguère C, Laroche C, Vaillancourt V, et al. Modelling speech intelligibility in the noisy work-place for normal-hearing and hearing-impaired listeners using hearing protectors. Int J Acoust Vib. 2010;15:156-167.

[30] Kryter KD. Effects of Ear Protective Devices on the Intelligibility of Speech in Noise. J Acoust Soc Am. 1946;18:413-417.

[31] Suter AH. Communication and job performance in noise : A review. Rockville (MD): American Speech-Language-Hearing Association; 1992.

[32] Zheng Y, Giguère C, Laroche C, et al. A Psychoacoustical Model for Specifying the Level and Spectrum of Acoustic Warning Signals in the Workplace. J Occup Environ Hyg. 2007;4:87-98.

[33] Zimpfer V, Sarafian D. Impact of hearing protection devices on sound localization performance. Front Neurosci. 2014;8:1-10.

[34] Giguère C, Berger EH. Speech recognition in noise under hearing protection: A computational study of the combined effects of hearing loss and hearing protector attenuation. Int J Audiol. 2016;55:S30-S40.

[35] Giguère C, Berger EH. Modeling the interaction between the hearing protector attenuation function and the hearing loss profile on sound detection in noise. Proc 10th Eur Congr Expo Noise Control Eng. Maastricht, Netherlands: EAA-NAGABAV; 2015. p. 1967-1972.

[36] Festen JM, Plomp R. Effects of fluctuating noise and interfering speech on the speech- reception threshold for impaired and normal hearing. J Acoust Soc Am. 1990;88:1725-1736.

[37] Casali JG, Park M-Y. Attenuation performance of four hearing protectors under dynamic movement and different user fitting conditions. Hum Factors. 1990;32:925 . 
[38] Casali JG, Park M-Y. Effects of work conditions simulated in a laboratory environment and wearer fit on attenuation of slow-recovery foam earplugs. J Sound Vib. 1990;143:153-165.

[39] Joseph A, Punch J, Stephenson M, et al. The effects of training format on earplug performance. Int J Audiol. 2007;46:609-618.

[40] Murphy WJ, Stephenson MR, Byrne DC, et al. Effects of training on hearing protector attenuation. Noise Health. 2011;13:132.

[41] Abaza A, Hebert C, Harrison MAF. Fast learning ear detection for real-time surveillance. 2010 Fourth IEEE Int Conf Biom Theory Appl Syst BTAS. Washington (DC): IEEE; 2010. p. 1-6.

[42] Verma P. Morphological Variations and Biometrics of Ear: An Aid to Personal Identification. J Clin Diagn Res. 2016;10:138-142.

[43] Lee W, Yang X, Jung H, et al. Anthropometric analysis of 3D ear scans of Koreans and Caucasians for ear product design. Ergonomics. 2018;61:1480-1495.

[44] Pirzanski C, Berge B. Ear canal dynamics: Facts versus perception. Hear J. 2005;58:50.

[45] Wheeler DE, Glorig A. The Industrial Hygienist and Ear Protection. Noise Control. $1956 ; 2: 45-72$.

[46] Cunningham DJ, Robinson A. Cunningham's textbook of anatomy. 5th ed. New York (NY): William Wood and company; 1918.

[47] Samelli AG, Gomes RF, Chammas TV, et al. The study of attenuation levels and the comfort of earplugs. Noise Health. 2018;20:112-119.

[48] Thomas WC, Wright WH, Casali J. G. Ear Canal Measurement: Eargage Versus Ear Impressions. 19th Annu NHCA Conf Spectr 11 Suppl 1. Virginia Tech; 1994. p. 34.

[49] Fu F, Luximon Y. A systematic review on ear anthropometry and its industrial design applications. Hum Factors Ergon Manuf Serv Ind. 2020;30:176-194.

[50] Stefanson JRW, Ahroon WA. Evaluation of digital ear scanning for custom hearing protection devices. J Acoust Soc Am. 2019;146:2917-2917.

[51] Chiou WK, Huang DH, Chen BH. Anthropometric Measurements of the External Auditory Canal for Hearing Protection Earplug. Proc AHFE 2016. Walt Disney World, Florida, USA: Springer Berlin Heidelberg; 2016. p. 163-171.

[52] Yu J-F, Lee K-C, Wang R-H, et al. Anthropometry of external auditory canal by noncontactable measurement. Appl Ergon. 2015;50:50-55. 
[53] Darkner S, Larsen R, Paulsen RR. Analysis of deformation of the human ear and canal caused by mandibular movement. In : Ayache N., Ourselin S., Maeder A. (eds) Medical Image Computing and Computer-Assisted Intervention - MICCAI 2007. Lect Notes Comput Sci. Springer,. Berlin, Heidelberg; 2007. p. 801-808.

[54] Bockstael A, Keppler H, Botteldooren D. Musician earplugs: Appreciation and protection. Noise Health. 2015;17:198-208.

[55] Bjorn VS, Albery CB, McKinley RL. US Navy flight deck hearing protection use trends: survey results. Patuxent River (MD): Naval Air Warfare Center Aircraft Division; 2006. Report No.: NAWCADPAX/TR-2006/73.

[56] Spomer J, Estrich CG, Halpin D, et al. Clinician Perceptions of 4 Hearing Protection Devices. JDR Clin Transl Res. 2017;2:363-369.

[57] Davis RR, Murphy WJ, Byrne DC, et al. Acceptance of a Semi-Custom Hearing Protector by Manufacturing Workers. J Occup Environ Hyg. 2011;8:D125-D130.

[58] Byrne DC, Davis RR, Shaw PB, et al. Relationship between comfort and attenuation measurements for two types of earplugs. Noise Health. 2011;13:86-92.

[59] Acton WI. Speech Intelligibility in a Background Noise and Noise-induced Hearing Loss. Ergonomics. 1970;13:546-554.

[60] Killion MC. Factors influencing use of hearing protection by trumpet players. Trends Amplif. 2012;16:173-178.

[61] Huttunen KH, Sivonen VP, Pöykkö VT. Symphony orchestra musicians' use of hearing protection and attenuation of custom-made hearing protectors as measured with two different real-ear attenuation at threshold methods. Noise Health. $2011 ; 13: 176$.

[62] Reber MB, Kompis M. Acclimatization in first-time hearing aid users using three different fitting protocols. Auris Nasus Larynx. 2005;32:345-351.

[63] Behar A, Segu R, Russo F. Comfort from Hearing Protectors. Can Acoust. 2014;42.

[64] Stork RL, Gasaway DC. Evaluation of V-51R and EAR (tm) earplugs for use in flight. Brooks Air Force Base (TX): USAF School of Aerospace Medicine, Aerospace Medical Division; 1977. p. 10. Report No.: SAM-TR-77-1.

[65] Gasaway DC. Aeromedical Review: Personal Ear Protection (Attenuation, effectiveness, and wearability of ear protection devices). Brooks Field (TX): School of aerospace medicine; 1971. Report No.: SAM-Review-2-71.

[66] Franks JR. Why Choose Custom-Moulded Over Disposable Earplugs? Ind Saf Hyg News. 2012 Aug; 14. 
[67] Marshall L, Weathersby P, McCluskey J, et al. The Introduction of Custom Earplugs Aboard LCS-1. Groton (CT): Naval Submarine Medical Research Laboratory; 2016. Report No.: NSMRL/F1401/TM--2016-1315.

[68] Svensson EB, Morata TC, Nylén P, et al. Beliefs and attitudes among Swedish workers regarding the risk of hearing loss. Int J Audiol. 2004;43:585-593.

[69] Morata TC, Johnson A-C, Nylen P, et al. Audiometric Findings in Workers Exposed to Low Levels of Styrene and Noise: J Occup Environ Med. 2002;44:806-814.

[70] Bramhall N, Beach EF, Epp B, et al. The search for noise-induced cochlear synaptopathy in humans: Mission impossible? Hear Res. 2019;377:88-103.

[71] Le Prell CG. Effects of noise exposure on auditory brainstem response and speechin-noise tasks: a review of the literature. Int J Audiol. 2019;58:S3-S32.

[72] Liberman MC. Noise-induced and age-related hearing loss: new perspectives and potential therapies. F1000Research. 2017;6:927.

[73] Neitzel R, Somers S, Seixas N. Variability of Real-World Hearing Protector Attenuation Measurements. Ann Occup Hyg. 2006,50:679-691.

[74] Laitinen H, Poulsen T. Questionnaire investigation of musicians' use of hearing protectors, self reported hearing disorders, and their experience of their working environment. Int J Audiol. 2008;47:160-168.

[75] Murphy WJ, Byrne DC, Themann CL. Hearing Protector Fit Testing. NHCA Annu Conf. Orlando, FL, USA; 2019.

[76] Berger EH. "Calibrating" the insertion depth of roll-down foam earplugs. Proc ICA 2013. Montreal, QC, Canada: Acoustical Society of America; 2013. p. 3235.

[77] American National Standards Institute (ANSI) and Acoustical Society of America (ASA). Performance Criteria for Systems that Estimate the Attenuation of Passive Hearing Protectors for Individual Users. New York (NY); 2018. Standard No.: ANSI/ASA S12.71.

[78] Martin L, Negrini A, Gaudreau MA, et al. Earplug personal attenuation rating (PAR) in noise-exposed workers: evolution over a five weeks follow-up. Proc 26th Int Congr Sound Vib ICSV26. Montreal, Canada: Canadian Acoustical Association; 2019.

[79] Voix J, Smith P, Berger EH. Field fit-testing and attenuation-estimation procedures. In: The Noise Manual, 6th edition (in press). American Industrial Hygiene Association. Falls Church (VA): AIHA Press; Forthcoming. p. 39. 
[80] Casali JG. Comfort: the "other" criterion for hearing protector design and selection. Proc Hear Conserv Conf. University of Kentucky, Lexington, Kentucky, USA; 1992. p. $47-53$.

[81] Brueck L. Assessment of subjective and objective measurement systems of earplug attenuation on an individual. Buxton, Derbyshire, England: Health and Safety Executive, Engineering and personal safety unit; 2013. p. 37. Report No.: RR975. .

[82] Murphy WJ, Byrne DC, Gauger D, et al. Results of the National Institute for Occupational Safety and Health-U.S. Environmental Protection Agency Interlaboratory Comparison of American National Standards Institute S12.6-1997 Methods A and B. J Acoust Soc Am. 2009;125:3262.

[83] Nélisse H, Le Cocq C, Boutin J, et al. Systematic evaluation of the relationship between physical and psychoacoustical measurements of hearing protectors' attenuation. J Occup Environ Hyg. 2015;12:829-844.

[84] Viallet G, Sgard F, Laville F, et al. Investigation of the variability in earplugs sound attenuation measurements using a finite element model. Appl Acoust. 2015;89:333344. 